\title{
Anti-Inflamatory Activity of Neolignan Compound Isolated from the Roots of Saururus chinensis
}

\author{
Sae-Rom Yoo®, Hyekyung Ha ${ }^{\circledR}$, Hyeun-Kyoo Shin and Chang-Seob Seo *® \\ Korea Institute of Oriental Medicine, Daejeon 34054, Korea; k2aori@kiom.re.kr (S.-R.Y.); hkha@kiom.re.kr (H.H.); \\ hkshin@kiom.re.kr (H.-K.S.) \\ * Correspondence: csseo0914@kiom.re.kr; Tel.: +82-42-868-9361
}

Received: 6 July 2020; Accepted: 22 July 2020; Published: 23 July 2020

\begin{abstract}
Saururus chinensis (Lour.) Baill. is a perennial herb and grows in Korea, China, and Japan. Interestingly, (7S,8S)- $\Delta^{8^{\prime}}-3,4$-methylenedioxy-3',5,5'-trimethoxy-7-monoacetate-8.O.4'-neolignan (MTMN), one of the active neolignans, was first isolated from the roots of Saururus chinensis. The compound was screened for anti-inflammatory activity using a RAW264.7 murine macrophage cell line. The dried roots of S. chinensis $(9.7 \mathrm{~kg}$ ) were extracted with $70 \%$ methanol and then solvent fractionation. From the ethyl acetate fraction, MTMN was purified through silica gel column and reverse-phase column chromatography and its structure was identified by spectroscopic analysis with nuclear magnetic resonance, circular dichroism, and mass spectrometry. RAW264.7 cells were induced using lipopolysaccharide (LPS) and treated with or without MTMN. Production of nitric oxide $(\mathrm{NO})$ and prostaglandin $\mathrm{E}_{2}\left(\mathrm{PGE}_{2}\right)$ levels were measured and protein expressions of nitric oxide synthase (iNOS) and cyclooxygenase-2 (COX-2) were analyzed by immunoblotting. The isolated neolignan was $(7 \mathrm{~S}, 8 \mathrm{~S})-\Delta^{8^{\prime}}$-3,4-methylenedioxy-3',5,5' -trimethoxy-7-monoacetate-8.O.4' ${ }^{\prime}$-neolignan. This compound suppressed the LPS-induced iNOS and COX-2 protein expressions, which led to a decrease in the production of $\mathrm{NO}$ and $\mathrm{PGE}_{2}$ levels. Further studies, including in animal models, will be required to establish the precise pharmacological effect of MTMN.
\end{abstract}

Keywords: Saururus chinensis; neolignan; inflammation

\section{Introduction}

Inflammation is a biological response that protects the body against harmful stimuli. Inflammatory abnormalities underlie a number of diseases including atherosclerosis [1], mental illness [2,3], sarcopenia [4], and obesity [5]. For over a decade, nonsteroidal anti-inflammatory drugs (NSAIDs) have been commonly used to alleviate inflammatory abnormalities. Although their side effects depend on the specific drug, the adverse effects of long-term use of NSAIDs include an increased risk of gastrointestinal disorders, myocardial infarction, and renal disease [6]. Therefore, recent studies in search of anti-inflammatory agents have focused on plant-derived medications, which are known for having relatively fewer side effects than conventional therapy.

Saururus chinensis (Lour.) Baill. (family: Saururaceae), commonly known as "Asian lizard's tail" [7] is a perennial herb and distributed in parts of East Asia, including Korea, China, and Japan. In Korean folk remedy, it is widely used for the treatment of edema, bladder infection, and several inflammatory diseases [8]. The root of $S$. chinensis contains various kinds of lignans including saucerneol, di-O-methyltetrahydrofuriguaiacin B, machilin D, and sauchinone [9-12], some of which have anti-inflammatory or antioxidant effects $[10,13,14]$.

In this study, we isolated a new 8-O-4' type neolignan, (7S,8S)- $\Delta^{8^{\prime}}-3,4$-methylenedioxy $-3^{\prime}, 5,5^{\prime}-$ trimethoxy-7-monoacetate-8.O.4'-neolignan (MTMN), from the roots of $S$. chinensis. This article presents the isolation, structural elucidation, and anti-inflammatory effects of this compound. 


\section{Results and Discussion}

\subsection{Structure Determination of MTMN}

Compound 1 was obtained as a sticky solid, with a molecular formula of $\mathrm{C}_{24} \mathrm{H}_{28} \mathrm{O}_{8}$ determined by high-resolution electrospray ionization mass spectrometry (HRESIMS, $m / z$; found $447.1683[\mathrm{M}+\mathrm{Na}]^{+}$; calcd 447.1682) (Figure S1). Seven methine groups, three methylene groups, two methyl groups, nine quaternary carbons, and three methoxyl groups were identified in the ${ }^{1} \mathrm{H}-\mathrm{NMR},{ }^{13} \mathrm{C}-\mathrm{NMR}, \mathrm{DEPT} 135$, and DEPT90 spectrum of 1 (Figure S2). The ${ }^{1} \mathrm{H}-\mathrm{NMR}$ spectrum exhibited two distinct methyl groups (H-9 and $\left.\mathrm{OAc}-\mathrm{CH}_{3}\right)$, three methoxyl groups $\left(5-\mathrm{CH}_{3}, 3^{\prime}-\mathrm{CH}_{3}\right.$, and $\left.5^{\prime}-\mathrm{CH}_{3}\right)$, one methylenedioxy group $\left(\mathrm{OCH}_{2} \mathrm{O}-3,4\right)$, one methylene group $\left(\mathrm{H}-9^{\prime}\right)$, and four aromatic protons $\left(\mathrm{H}-2, \mathrm{H}-6, \mathrm{H}-2^{\prime}\right.$, and $\left.\mathrm{H}-6^{\prime}\right)$. In the heteronuclear multiple bond correlation spectrum of $\mathbf{1}$ (Figure $1 \mathrm{~b}$ and Figure S3), long-range correlations of C-7 with H-2, H-6, H-8 and H-9 were observed. C-7' showed long-range correlations with H-9' , H-2', and $\mathrm{H}-6^{\prime}$. In addition, the ketone group of 7-monoacetate showed a long-range correlation with $\mathrm{H}-7$. The circular dichroism (CD) spectrum (Figure S4) was measured to determine the configurations at C-7 and $\mathrm{C}-8$ of compound $\mathbf{1}$. The results revealed that the CD spectrum of $\mathbf{1}$ showed positive signs in the region of 240-400 nm, indicating the 8S-configuration compared with those of reported analogs [15-17]. Furthermore, we confirmed the threo-configuration between $\mathrm{H}-7$ and $\mathrm{H}-8$ by confirming the large coupling constant $\left(J_{7,8}=7.3 \mathrm{~Hz}\right)$ according to previous studies [18,19]. The basis of these data and reported literature, $\mathbf{1}$, was determined to be (7S,8S)- $\Delta^{8^{\prime}}$-3,4-methylenedioxy-3' $, 5,5^{\prime}$-trimethoxy-7-monoacetate-8.O.4' -neolignan, which was first isolated and reported in this study.

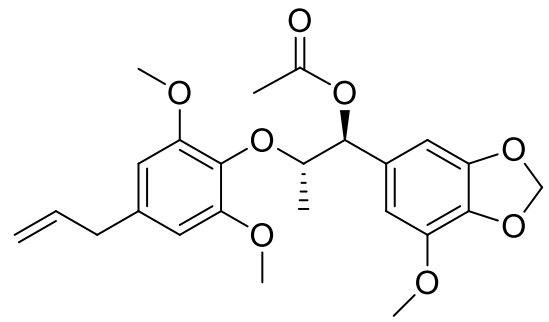

(a)

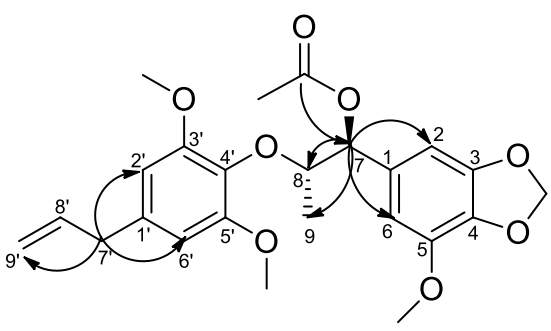

(b)

Figure 1. (a) Chemical structure and (b) key heteronuclear multiple bond correlation of compound $\mathbf{1 .}$

\subsection{Inhibitory Effect of Inflammation Related Mediator of MTMN}

Macrophages are a major component of the innate immune system, which modulates inflammatory responses and tissue homeostasis [20]. Lipopolysaccharide (LPS) is a well-known activator of macrophage and activated macrophage leads to the production of inflammatory mediators including cytokines, NO, and prostaglandins [20-22]. In this study, we determined the anti-inflammatory mediators affected by MTMN in the LPS-stimulated mouse murine macrophage RAW264.7 cell line. We evaluated the cytotoxicity of MTMN following the treatment of RAW264.7 cells with various concentration for $24 \mathrm{~h}$. MTMN has no toxicity up to $25 \mu \mathrm{M}$ treatment (data not shown). Thus, nontoxic concentrations of MTMN were used for all subsequent experiments.

Nitric oxide synthase (iNOS) is produced in response to bacterial products and inflammatory cytokines [21], and iNOS-derived NO is closely related to inflammatory processes. NO plays a role in various physiological and pathological processes, excessive production of NO may lead to inflammation response. As expected, LPS significantly increased the level of NO $(9.53 \pm 0.34 \mu \mathrm{M})$ and the expression of iNOS in RAW264.7 cells (Figure 2a,b). By contrast, MTMN downregulated the expression of iNOS at a concentration of $25 \mu \mathrm{M}$. The LPS-stimulated NO level was decreased by MTMN at a concentration of $25 \mu \mathrm{M}$ by $6.11 \pm 0.43 \mu \mathrm{M}(p<0.05)$. L-NG-monomethyl arginine (L-NMMA), as a non-selective inhibitor of NOS, also significantly decreased the level of NO production by $1.96 \pm 0.27 \mu \mathrm{M}$ in LPS-treated RAW264.7 cell. 


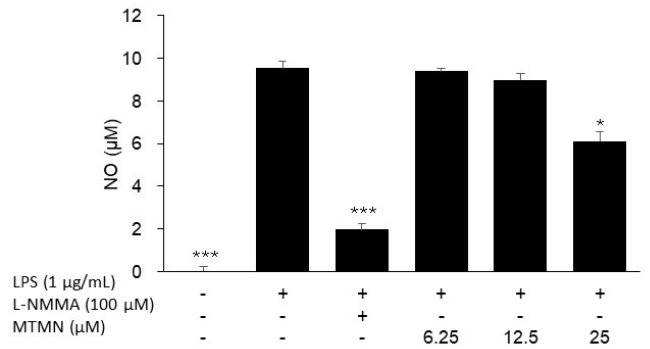

(a)

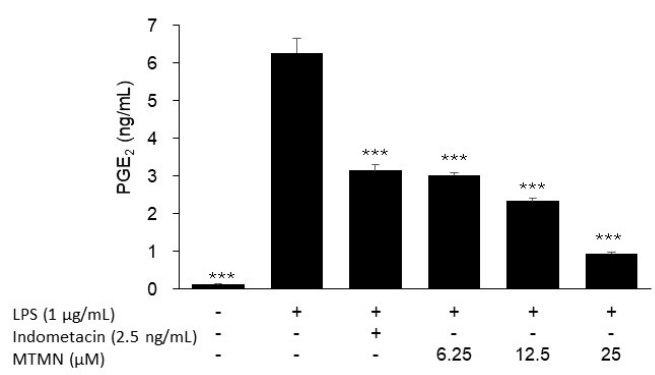

(c)

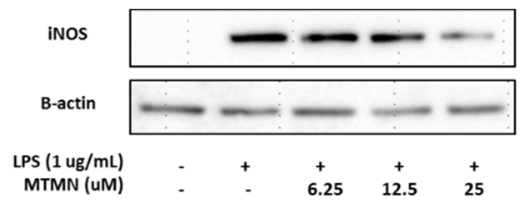

(b)

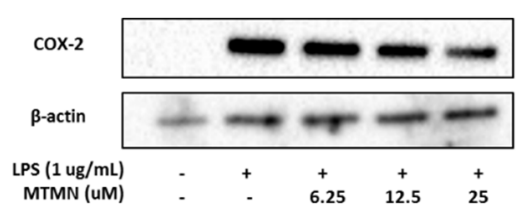

(d)

Figure 2. Effect of $(7 S, 8 S)-\Delta^{8^{\prime}}-3,4$-methylenedioxy-3' $, 5,5^{\prime}$-trimethoxy-7-monoacetate-8.O. $4^{\prime}$-neolignan (MTMN) on the production of nitric oxide (NO) (a) and prostaglandin $E_{2}$ (PGE2) (c), the expression of nitric oxide synthase (iNOS) (b) and cyclooxygenase-2 (COX-2) (d) in lipopolysaccharide (LPS)-stimulated RAW264.7 murine macrophage cell line. Data are presented as the mean \pm SEM. ${ }^{*} p<0.05$ and ${ }^{* * *} p<0.001$ are compared with the LPS only treated group.

Cyclooxygenase (COX) plays important roles in the biosynthesis of PG from arachidonic acid. COX-2 as COX isoform is an early-response gene that is highly inducible by stimuli such as LPS. One of the key downstream products of COX-2, prostaglandin $\mathrm{E}_{2}\left(\mathrm{PGE}_{2}\right)$, is a key mediator of inflammatory pain sensitization. Thus, inhibition of COX-2 blocks the synthesis of $\mathrm{PGE}_{2}$, and as a result, they suppress inflammation and attenuate pain. As shown in Figure 2c,d, LPS stimulation significantly increased the levels of $\mathrm{PGE}_{2}(6.26 \pm 0.39 \mathrm{ng} / \mathrm{mL})$ and expression of COX-2 compared with the LPS untreated control cell. In contrast, MTMN downregulated the expression of COX-2. Consistent with the immunoblotting results, $\mathrm{PGE}_{2}$ secretion was suppressed by MTMN in a dose-dependent manner $(3.03 \pm 0.05 \mathrm{ng} / \mathrm{mL}$ at $6.25 \mu \mathrm{M}, 2.33 \pm 0.08 \mathrm{ng} / \mathrm{mL}$ at $12.5 \mu \mathrm{M}$, and $0.95 \pm 0.02 \mathrm{ng} / \mathrm{mL}$ at $25 \mu \mathrm{M})$. Indomethacin, as an inhibitor of $\mathrm{PGE}_{2}$, also decreased the level of $\mathrm{PGE}_{2}(3.15 \pm 0.16 \mathrm{ng} / \mathrm{mL})$ in LPS- treated RAW264.7 cell.

\section{Materials and Methods}

\subsection{General Experimental Procedures}

Optical rotation and circular dichroism (CD) were measured using a JASCO DIP-1000 (Tokyo, Japan) automatic digital polarimeter and a JASCO J-1500 spectro-polarimeter (Tokyo, Japan) at $25^{\circ} \mathrm{C}$. The proton nuclear magnetic resonance $\left({ }^{1} \mathrm{H}-\mathrm{NMR}(250 \mathrm{MHz})\right.$ and $\left.{ }^{13} \mathrm{C}-\mathrm{NMR}(62.9 \mathrm{MHz})\right)$ were used on a Bruker AMX250 spectrometer (Karlsruhe, Germany). Samples were dissolved in $\mathrm{CDCl}_{3}$ and reported in ppm downfield from tetramethylsilane. The molecular mass value of the compound was analyzed using Synapt G2 HDMS quadrupole time-of-flight mass spectrometer equipped with an electrospray ion source (Waters, Milford, MA, USA). The stationary phases used for column chromatography (Silica gel 60, 70-230 and 230-400 mesh and Lichroprep RP-18 gel, 40-63 $\mu \mathrm{m}$, Merck) and thin layer chromatography (TLC) supplemented with $5.5 \%$ heat-inactivated fetal bovine serum (Gibco Inc.), penicillin $(100 \mathrm{U} / \mathrm{mL})$, and streptomycin $(100 \mu \mathrm{g} / \mathrm{mL})$. 


\subsection{Cytotoxicity Assay}

$5 \times 10^{3}$ cells were plated onto a 96-well microplate and treated with various concentrations of MTMN for $24 \mathrm{~h}$. Cytotoxicity of MTMN was detected using a Cell Counting Kit-8 (CCK-8; Dojindo, Kumamoto, Japan).

\subsection{Determination of Nitric Oxide (NO) and Prostaglandin $E_{2}\left(P G E_{2}\right)$}

RAW264.7 cells were treated with various concentrations of MTMN with lipopolysaccharide (LPS $1 \mu \mathrm{g} / \mathrm{mL}$ ) for $18 \mathrm{~h}$. After incubation, the collected supernatant was analyzed for generated nitrite concentration using a Gress reagent system (Promega, Madison, WI, USA). Production of $\mathrm{PGE}_{2}$ in the culture supernatant was measured using ELISA kits from Cayman Chemical Co. (Ann Arbor, MI, USA).

\subsection{Western Blotting}

RAW264.7 cells were treated with various concentrations of MTMN, with or without LPS $(1 \mu \mathrm{g} / \mathrm{mL})$, for $18 \mathrm{~h}$. Cells were lysed with a lysis buffer containing protease/phosphatase inhibitor cocktail (Cell Signaling Tech., MA, USA). An equal amount of proteins was resolved by SDS-PAGE gels and then transferred onto polyvinylidene difluoride membranes (Millipore, MA, USA). Inducible nitric oxide synthase (iNOS) and cyclooxygenase (COX)-2 antibodies were used to detect respective proteins and the immunoreactive bands were developed using an enhanced chemiluminescence (ECL) reagent (Thermo Scientific, Rockford, IL, USA). Analyses were carried out in triplicate.

\subsection{Statistical Analysis}

All experiments were performed in triplicate. The data are presented as mean \pm standard error of the mean (SEM). Significant differences were assessed using a one-way analysis of variance and post hoc Bonferroni correction using SYSTAT (Systat Software Inc., Chicago, IL, USA). A $p$-value less than 0.05 (typically $\leq 0.05$ ) is statistically significant.

\section{Conclusions}

The 8.O.4' -Type neolignan, $(7 S, 8 S)-\Delta^{8^{\prime}}-3,4$-methylenedioxy-3',5,5'-trimethoxy-7-monoacetate8.O.4'-neolignan, was first isolated from the ethyl acetate fraction of the $S$. chinensis root extract. The structure of this compound was determined based on spectroscopic data, NMR, MS, and CD.

The isolated compound inhibited the LPS-stimulated production of proinflammtory mediators $\mathrm{NO}$ and $\mathrm{PEG}_{2}$, and related protein expressions of iNOS and COX-2. Further investigation is needed to establish a specific mechanism involved in the anti-inflammatory effect of MTMN.

Supplementary Materials: The following are available online at http://www.mdpi.com/2223-7747/9/8/932/s1, Figure S1: HRESIMS spectrum of compound 1, Figure S2: ${ }^{1} \mathrm{H}-\mathrm{NMR},{ }^{13}$-NMR, DEPT135, and DEPT90 spectra of compound 1, Figure S3: HMBC spectrum of compound 1, Figure S4: CD spectrum of compound 1.

Author Contributions: C.-S.S. conceived and designed the experiments; C.-S.S. performed the experiments for extraction and isolation; S.-R.Y. performed the cell experiments; C.-S.S., S.-R.Y. and H.H. analyzed the data; C.-S.S. and S.-R.Y. wrote a draft manuscript. C.-S.S., S.-R.Y., H.H. and H.-K.S. edited and revised manuscript. All authors have read and agreed to the published version of the manuscript.

Funding: This work was supported by grants from the Korea Institute of Oriental Medicine (KSN2013310).

Conflicts of Interest: The authors have declared that they have no conflict of interest.

\section{References}

1. Pirillo, A.; Bonacina, F.; Norata, G.D.; Catapano, A.L. The Interplay of Lipids, Lipoproteins, and Immunity in Atherosclerosis. Curr. Atheroscler. Rep. 2018, 20, 12. [CrossRef] [PubMed]

2. Herron, J.W.; Nerurkar, L.; Cavanagh, J. Neuroimmune Biomarkers in Mental Illness. Curr. Top. Behav. Neurosci. 2018, 40, 45-78. [PubMed] 
3. Miller, A.H.; Raison, C.L. The role of inflammation in depression: From evolutionary imperative to modern treatment target. Nat. Rev. Immunol. 2016, 16, 22-34. [CrossRef] [PubMed]

4. Wang, J.; Leung, K.S.; Chow, S.K.; Cheung, W.H. Inflammation and age-associated skeletal muscle deterioration (sarcopaenia). J. Orthop. Translat. 2017, 10, 94-101. [CrossRef] [PubMed]

5. Avalos, Y.; Kerr, B.; Maliqueo, M.; Dorfman, M. Cell and molecular mechanisms behind diet-induced hypothalamic inflammation and obesity. J. Neuroendocrinol. 2018, 30, e12598. [CrossRef] [PubMed]

6. Bally, M.; Dendukuri, N.; Rich, B.; Nadeau, L.; Helin-Salmivaara, A.; Garbe, E.; Brophy, J.M. Risk of acute myocardial infarction with NSAIDs in real world use: Bayesian meta-analysis of individual patient data. BMJ Br. Med. J. 2017, 357. [CrossRef] [PubMed]

7. Arboretum, K.N. English Names for Korean Native Plants; Korea National Arboretum: Pocheon, Korea, 2015; p. 778.

8. Park, J.H.; Lee, J.G. The Encycolpedia of Medicinal Plants; Shin Il Publishing Co.: Seoul, Korea, 2000; pp. $202-203$.

9. Li, C.; Li, N.; Yue, J.; Song, Q.; Fan, Q. Two new lignans from Saururus chinensis. Nat. Prod. Res. 2017, 31, 1598-1603. [CrossRef] [PubMed]

10. Seo, C.S.; Lee, Y.K.; Kim, Y.J.; Jung, J.S.; Jahng, Y.; Chang, H.W.; Song, D.K.; Son, J.K. Protective effect of lignans against sepsis from the roots of Saururus chinensis. Biol. Pharm. Bull. 2008, 31, 523-526. [CrossRef] [PubMed]

11. Seo, C.S.; Zheng, M.S.; Woo, M.H.; Lee, C.S.; Lee, S.H.; Jeong, B.S.; Chang, H.W.; Jahng, Y.; Lee, E.S.; Son, J.K. Lignans from the roots of Saururus chinensis. J. Nat. Prod. 2008, 71, 1771-1774. [CrossRef] [PubMed]

12. Sung, S.H. A new dineolignan from Saururus chinensis root. Fitoterapia 2006, 77, 487-488. [CrossRef] [PubMed]

13. Li, B.; Lee, D.S.; Choi, H.G.; Kim, K.S.; Kang, D.G.; Lee, H.S.; Jeong, G.S.; Kim, Y.C. Sauchinone Suppresses Pro-inflammatory Mediators by Inducing Hesla me Oxygenase-1 in RAW264.7 Macrophages. Biol. Pharm. Bull. 2011, 34, 1566-1571. [CrossRef] [PubMed]

14. Park, G.; Kim, H.G.; Sim, Y.; Sung, S.H.; Oh, M.S. Sauchinone, a Lignan from Saururus chinensis, Protects Human Skin Keratinocytes against Ultraviolet B-Induced Photoaging by Regulating the Oxidative Defense System. Biol. Pharm. Bull. 2013, 36, 1134-1139. [CrossRef] [PubMed]

15. Silva, M.S.; Barbosa-Filho, J.M.; Yoshida, M.; Gottlieb, O.R. Benzodioxane and $\beta$-aryloxy-arylpropane type neolignans from Licaria chrysophylla. Phytochemistry 1989, 28, 3477-3482. [CrossRef]

16. Fang, J.M.; Lee, C.K.; Cheng, Y.S. Lignans from leaves of Juniperus chinensis. Phytochemistry 1992, 31, 3659-3661.

17. Lee, I.S.; Kim, Y.S.; Jung, S.H.; Yu, S.Y.; Kim, J.H.; Sun, H.; Kim, J.S. Lignans from the stems and leaves of Brandisia hancei and their effects on VEGF-induced vascular permeability and migration of HRECs and DLAV formation in zebrafish. Biosci. Biotechnol. Biochem. 2015, 79, 581-586. [CrossRef] [PubMed]

18. Barata, L.E.S.; Baker, P.M.; Gottlieb, O.R.; Rùveda, E.A. Neolignans of Virola surinamensis. Phytochemistry 1978, 17, 783-786. [CrossRef]

19. Conserva, L.M.; da Silva, M.S.; Filho, R.B. Lignans from Aristolochia birostris. Phytochemistry 1990, 29, 257-260. [CrossRef]

20. Fujiwara, N.; Kobayashi, K. Macrophages in inflammation. Curr. Drug Targets Inflamm. Allergy 2005, 4, 281-286. [CrossRef] [PubMed]

21. Moncada, S.; Palmer, R.M.; Higgs, E.A. Nitric oxide: Physiology, pathophysiology, and pharmacology. Pharmacol. Rev. 1991, 43, 109-142. [PubMed]

22. Williams, C.S.; Mann, M.; DuBois, R.N. The role of cyclooxygenases in inflammation, cancer, and development. Oncogene 1999, 18, 7908-7916. [CrossRef] [PubMed]

(C) 2020 by the authors. Licensee MDPI, Basel, Switzerland. This article is an open access article distributed under the terms and conditions of the Creative Commons Attribution (CC BY) license (http://creativecommons.org/licenses/by/4.0/). 